\title{
Can Digital Games Be a Way of Improving the Neuroplasticity in Stroke Damage? Can the Adult Brain Grow New Cells or Rewire Itself in Response to a New Experience?
}

\author{
Livia Stocco Sanches Valentin \\ Department of Anesthesiology, School of Medicine, University of Sao Paulo, Sao Paulo, Brazil \\ Email: 1ssv@usp.br
}

How to cite this paper: Valentin, L.S.S. (2017) Can Digital Games Be a Way of Improving the Neuroplasticity in Stroke Damage? Can the Adult Brain Grow New Cells or Rewire Itself in Response to a New Experience? Open Journal of Medical Psychology, 6, 153-165.

https://doi.org/10.4236/ojmp.2017.62013

Received: January 15, 2017

Accepted: April 25, 2017

Published: April 28, 2017

Copyright $\odot 2017$ by author and Scientific Research Publishing Inc. This work is licensed under the Creative Commons Attribution International License (CC BY 4.0).

http://creativecommons.org/licenses/by/4.0/

\begin{abstract}
Exploratory studies developed at several neurosciences laboratories at universities around the world show us through the experience that there is a biological process called neuroplasticity. Because of this oldest concept about the neuronal formation, scientists also thought that if a particular area of the adult brain was damaged, the nerve cells could not form new connections and the functions controlled by this field of the brain would be permanently lost or could not be regenerate. However, studies have overturned this old view, and currently, scientists recognize that the brain continues to reorganize itself by forming new neural connections during the life. This phenomenon is called neuroplasticity that refers to the potential which the brain should be reorganized by creating new neural pathways to adapt, as it needs.
\end{abstract}

\section{Keywords}

Neuroplasticity, Neuropsychology Rehabilitation, Digital Games

\section{Introduction}

Exploratory studies developed at several neurosciences laboratories at universities around the world show us through the experience that there is a biological process called neuroplasticity [1].

Because of this oldest concept about the neuronal formation, scientists also thought that if a particular area of the adult brain was damaged, the nerve cells could not form new connections and the functions controlled by this field of the brain would be permanently lost or could not be regenerate [2].

However, studies have overturned this old view, and currently, scientists rec- 
ognize that the brain continues to reorganize itself by forming new neural connections during the life [3].

This phenomenon is called neuroplasticity that refers to the potential which the brain has to reorganize by creating new neural pathways to adapt, as it needs. Those studies arise anyways, which the brain can improve the skills. The Neuroplasticity allows the neurons in the brain to compensate for injury or damage and adjust their activity in response to new situations or changes in their environment [4].

The brain consists of around 100 billion neural cells that cannot generate new ones. Old studies showed that the generation of new neurons-knows as neurogenesis did not occur. This early studies assumed that each of brain was born with a finite number of neural cells and when a cell died, no new cell could grow. Thus, these researchers about the brain's inability to regenerate new neurons are no longer relevant. Studies identify that in particular areas, the brain can generate new nerves cells [5].

The synaptic transmission (neurotransmission) is the process by which signaling molecules (neurotransmitters) are released by a neuron on presynaptic (neuron) and bind to the activate receptors of another nerve cell called postsynaptic neuron [6]. Then, the neurotransmission is essential for the process of communication between two nerves cells. The key component of the nervous system is the neuron. This is a cell consisting of a cell body that receives the stimulation from other neurons through its branchlike dendrites. It then transmits the stimulation to other neurons through a cable-like axon [7].

The transmission of information within a neuron is electrical. The transmission of information between neurons is chemical. There is a gap between neurons called a synapse. The arrival of a signal at a synapse releases molecules called neurotransmitters. These electrical and chemical processes occur always allowing neurotransmitters to stimulate specific functions [8].

Neurons form elaborate networks through which nerve impulses (action potentials) travel. Each neuron has as many as 15,000 connections with other neurons. Neurons do not touch each other; instead, neurons interact at close contact points called synapses. A neuron transports its information by way of an action potential. When the nerve impulse arrives at the synapse, it may cause the release of neurotransmitters, which influence another neuron [9].

This new understanding of neural cell generation is an incredible discovery, and misconception was that the brain had an inability to create new neural pathways. Therefore, if there are neuroplasticity and the possibility of improving the brain skills, how to do this [10] [11]?

Neuroplasticity enables the brain to compensate for damage, but sometimes an area of the brain is so extensively damaged that its natural ability to reorganize is insufficient to regain the lost function. Dementia or others disease that compromises the cognitive functions, especially the memory or disorder that cause neuronal death, the death of many cells may render the brain unable to reorganize corrective connections [12]. Thus, if a brain "circuit" highly specialized is de- 
stroyed, the associated mental function may be lost. Currently there is no way of determining with certainty whether a lost function can be recovered [4]. However, there is another source of hope. Recent research has shown that the brain can sometimes generate new neurons, not simply new connections and that these new neurons can sometimes "migrate" within the brain. Raises the possibility that, under certain conditions, new neurons could migrate to damaged areas, form new connections, and restore some or all lost functions. It is too early to say for sure on this, still, have much to learn about neuroplasticity!

Everyone, principally researchers know that Billions of tree-shaped nerve cells make up the human brain. Research indicates that neurogenesis may well continue to occur throughout the human life span, although it occurs less rapidly in adults [13]. Most of the new neurons that form in adults die almost immediately, but the evidence suggests that some cells that can integrate themselves into the existing web of neural connections [14].

Neurons are produced through a process called neurogenesis, which begins during the third week of development in humans. Nerve cells develop at an average rate of 250,000 per minute during the prenatal period, but by birth, the process of neurogenesis has ceased largely [15].

\section{Discussion}

A widely held belief is that neurons, unlike other cells, cannot reproduce after the first few years of life, which would mean that neurons that were destroyed couldn't be replaced. But this concept left to be true approximately in 1999 when the production of new neurons discovered in the neocortex of adult primates. Researchers discovered neurogenesis occurring in the brains of adult humans. In this study, researchers identified new neurons and observed neurogenesis occurring in the hippocampal region, a brain region that controls certain types of memory [16].

Studies have shown through the used PET, and MRI brain scanning technology, those new neural cells are generated through life as well as new neural pathways [17] [18]. So, old brains are capable of creating measurable changes in brain organization. These changes are not always easy but can happen through stimulus focus on dysfunction area. The developing brain shows remarkable plasticity [19]. The developing brain changes so fast as it processes information from the outside world and continues to change through life. Early developmental psychologists believed that neural networks become stable over time, but more recent evidence suggests that the brain never stops changing [20]. This is the foundation of learning, in which stronger associations made through experience.

Sometimes, in the case of permanent injury, brain plasticity can allow another part of the brain to take over the function of the damaged part of the brain, like a stroke or dementia [21].

Cognition is a term applied to many complex mental processes which, together, enable us to understand and interact with the world around us [22]. This is where a supervisory process called executive function comes into play [23]. These 
ties in with our ability not only to focus our attention on specific things but also to divide our attention between competing tasks when required to do so.

Perception: We receive information from sight, sound, smell, taste, touch, and body position. This information processed rapidly and without awareness, to produce a mental representation, or perception, of the world around use that point in time.

Memory: Our minds are diverse. We have memories for both recent events and remote ones, for sounds and sights, for facts and figures, events and skills and so on. Such diversity suggests a complex system. Declarative memory is for events and circumstances. It requires active remembering this memory system may be divided further into episodic memory (events) and semantic memory (facts). Nondeclarative memory: consists of three subsystems, each of which relates to a different kind of learning. Here, the products of learning demonstrated by reproducing what were learned, rather than actively recalling data. Prospective memory is the power to remember to do things in the future. It requires both the declarative and nondeclarative system memory as well as executive functions such as planning or strategies.

Memory processes: Memory depends on the details with which information encoded, the degree to which it consolidated, and the efficiency with which it is found and retrieved. How this happens depends on the types of memories we have. Consolidation of a memory trace can be synaptic systemic. Synaptic consolidation is temporary and associated with short-term storage. Memories are processed in the brain by the hippocampus and stored remotely, in distributed locations across the cortex. The Executive Functions is a concept by the more important and manly function. Each of us relies on a dedicated number of processes which, acting together, priories and coordinate conscious mental activity. The first is automated and drives every day, highly repetitive behaviors such as going to work. These processes are complex tasks but so heavily overlearned that we carry them out without thinking. The seconds' system is the executive system that is required for all other complex tasks as a planning and prioritizing the stages involved, and coordinating perception memory. Together, these processes serve an executive function.

Attention: Some tasks demand our full attention; while others require us to divide our attention. Selective auditory attention is the ability to listen to one message while ignoring others. Selective visual attention has characterized as a spotlight that directs attention towards a selected target. When attention has to divide between simultaneous tasks, performance tends to deteriorate in comparison to focusing on one task. There is no doubt that both selective and divided attention an important skill when carrying out tasks.

Working Memory: We all have a mental workspace dedicated to things like mental arithmetic and problem-solving. The bigger this is the better. Attempts have been made to identify the structure of working memory and to assess the relationship between working memory capacity and performance. Alan Baddeley and Graham Hitch argued that working memory consists of a central execu- 
tive a director of operations if you like (1974) [24]. Its role is to allocate attention prioritize, and coordinate. Two slave systems serve it. The phonological loop holds and refreshes verbal information and is important in acquiring a vocabulary. The visual-spatial scratchpad keeps and refreshes visual and spatial information, and used when, say, copying a drawing.

The episodic buffer is an interface between the central executive, the two slave systems, and long-term memory [25]. Another important function of our brain is the language. A fundamental concept of these communication (language) skills is the mental lexicon, a dictionary that stores information about the sounds of words, their pronunciations, and their meanings. When speaking, sentences constructed in four stages a conceptual stage; and an articulatory stage.

Cognitive learning involves the conscious use of strategies to acquire new knowledge. Humans often learn by formulating and testing hypotheses. Using observation, existing evidence, a theory is developed and tested against new evidence. The hypothesis is then accepted, rejected or revised [26].

Assimilation of conceptually complex material is a cognitive learning strategy employed by students of all ages: understanding the material; organizing the material so that the different components are connected; embedding the new equipment within existing knowledge and final but no less important one testing one's knowledge of the material.

The question is how does neuroplasticity work. Focuses on this issue, researchers are confident that the brain continually adapts and reorganizes. Research about cognitive functions using fMRI found that the neuronal connections in many brain regions appear to be organized differently each time [18] [27].

There are neural pathways that are inactive or used for other issues show the skills to take over and carry out functions lost to degeneration. There is evidence that reorganization in the adult brain can even involve the formation of new neural connections [28] [29]. Therefore, understanding the brain's ability to reorganize itself dynamically can help the scientists understand how human sometimes recover brain functions damaged by injury or disease [30]. Gene is certainly the factor determining how the brain develops and forms its connections, but not only genetically the brain improves their ability. Conditions in an environment, such as social interactions, educational level, challenging experiences can play a crucial role in brain cell survival and the formation of connections [31]. It estimated that between $18-36 \%$ of people would experience some form of mental health difficulty throughout their lifetime, with one in four families expected to contain a member with [32]. Typically, diagnosis of a mental health disorder depends on the identification of a particular set of symptoms, often under a given set of circumstances [33]. Thus, the brain changes in response to environmental conditions can also change and rearrange in response to injury or disease. These changes or rearrangements also involve changes in the connection between linked neural cells, called neurons in the brain. Brain reorganization occurs where undamaged axons grow new nerve endings to re- 
connect the neurons, thus making new connections and new neural pathways to accomplish what was a damaged function. Finally, flexible and capable of such adaptation, the brain compensates for damage in effect by reorganizing and forming new connections between intact neurons. Many studies show that if the brain has a deficiency in one area or hemisphere, regularly this brain adapt the particular process in another field, for example, deaf people have the visual cortex frequently more accurately.

Concerning fell off of the question arises in this paper, can the adult brain grow new brain cells or rewire itself in response to new experience, we would like that the answer could be around a possible rehabilitation. But how can we do this? It's not at all entirely straightforward, but neither difficult as well.

On paragraph above we discuss the brain and their injuries or damages and possible reorganization as the capable adaptation to new connections between neuron cells. Will be that professionals health's will help during this process? Let us start a new topic about reorganization, and we will decide about this issue to the conclusion.

Brain change occurs to reconnect, and to this process, the neurons need to stimulate through activity or determinate tasks. Research in animals observed that when occur damaged a small brain area this injury will result in the loss of particular response by the stimulus. Due to the lack of activity, even the neurons surrounding the damaged brain area withered, resulting in further impairment of specific or generalize answer.

The conclusions confirm the notion that it is important to provide stimulation to neurons for them to remain active and form new connections and finally promoting rehabilitation [34]. Voilà that's it! I am afraid not! Unfortunately, the same brain reorganization may sometimes contribute to the symptoms of disease or impairment. For instance, people who are deaf sometimes suffer from a continual ringing in their ears, which may be the result of the rewiring of brain cells starved for sound. It is important to stimulate the neurons in just the right way for them to form beneficial new connections. By better understanding how the brain reorganizes itself, so the brain can better learn how this task can accomplish. The cerebral cortex adapts to changing environmental demands throughout an individual's life.

Another question is; how strategies for promoting brain reorganization could use? A principle of neuroplasticity is brain activity promotes brain reorganization and this way help the brain reorganize connections more quickly and when the mind is not capable of rearranging on its own [19]. Simple brain exercises with challenging intellectual environments, interacting in social situations, or getting involved in physical activities will boost the general growth of connections [35].

Scientists continue to investigate the workings of neuroplasticity and continue to ask how best to encourage this natural process of reorganization? Studies confirm that an active lifestyle maintains brain function; thus, new research aims to develop lifestyle behaviors and medications that could improve normal brain 
development as well as repair damaged brains [36]. This area of research, some scientists are exploring the ability of a, particularly stimulating environment to boost reorganization and repair damage.

Another way to promote neuronal connections in the brain has been the take drugs that increase the availability of the specifics hormones help in the rehabilitation [31]. These drugs stimulate or provoke the synapses of the nerve cells, making them more capable of forming new connections. It is important to know that drugs alone may not be the optimal approach to rehabilitation, mainly because the side effects, however, drugs may well be beneficial when used together with a third approach: rehabilitation therapy. Building on the principle that neuronal activity promotes new connections, rehabilitation therapy attempts to stimulate particular neurons that have not been active for some time. An important aspect of rehabilitation therapy is timing [37] [38]. When a brain is injured, probably lose cognitive functions and connections between them and are no longer possible to reconnect. Research shows that the ideal to be done after an injury is primarily let this brain recovers topographic injuries, this means injuries properly on the affected organ. This is because research has shown that the brain is stimulated soon after injury, the problem will tend to worsen, and scars will be permanent [20].

Satisfied, the rehabilitation must wait one or two weeks so that the area can stimulate new connections. In short, rehabilitation therapy can indeed take advantage of the natural flexibility of the brain to form new neural connections. However, this is a delicate process that must be done carefully and under professional guidance. The discovery of neurogenesis in the brain of adult humans has spurred an investigation of how to influence neural development as well as how to replace dying cells with new ones. In an attempt to increase the production of new neurons, scientists are experimenting with neuronal growth factors. Growth factors have been successful at stimulating stem cells to produce new neurons.

The future for people with brain damage may likely involve some combination of rehabilitation therapy, medication, and possibly, the transplantation of new brain cells into the damaged brain area. Unfortunately, the use of new neurons and growth factors for treatment is not yet ready for clinical use. Scientists need to learn more about how the process of neurogenesis controlled and how to successfully integrate the new neurons into the existing brain circuitry. As research continues, there is growing hope that science will discover a safe and effective way to guide the process of neuronal growth to repair areas of the brain that are damaged by injury or disease.

There are several types, which could improve the brain's skills, as a technique through electrostimulation on the affected area with Transcranial direct-current stimulation (tDCS) or other neurostimulation with tasks that improve the cognitive functions. The best way that we have found is rehabilitating the brain by video games [39] [40].

Another technique called Transcranial Magnetic Stimulation (TMS) may soon be very helpful for guiding the process of brain reorganization; however, this 
method requires more study before it is deemed safe and ready for clinical use. Scientists have used TMS to modify the process of improvement to enhance the benefits of "rewiring" TMS consists of a wire coil that produces a magnetic field, which surrounds the head and produces an electrical current in nearby regions of the brain. The electrical current is used to stimulate areas of the brain that will benefit from the input, and to prevent stimulation of brain regions where the formation of new connections is not beneficial. The ability to focus brain reorganization could bring about more rapid and more successful recoveries from damage to brain areas.

Then, could mindless video game play indeed trigger such stunning improvements in cognitive skills [41]? New research endeavor has led to assess the impact of video game play on both the brain and behavior. When we began our studies about postoperative cognitive dysfunction (POCD), we perceived that the decrease or impairment cognitive occurred just after surgery especially in elderly patients with lower educational level, poor socioeconomic status or widower. Thinking a manner to help these patients we created a useful and straightforward digital game similar a video game, which, offering to the player without playing ability a way to improve the brain's skills [42].

Thus, for the past a feel years, our investigations, coupled with those other labs around the world, have established that playing action video game can change some aspects of cognition for the better [43]. During this research, other teams and we have found that digital game plays boots a variety of cognitive functions. Studies show us that individuals who play action games demonstrate improved ability to focus on visual details, motor dexterity, solving the problem on mentally rotate objects more accurately so can judge how to achieve the real goal during many situations on the life [44].

Gaming playing seems to confer the ability to make correct decisions principally under pressure. One study revealed that surgeons who were also game players were able to complete surgeries more quickly while retaining the necessary precision in the operating room [45]. Another study showed that gameplaying surgeons appeared to work more efficiently, not just faster. Video games as learning tools might come considered as adverse effects on children who played games such as "Doom" [45].

\section{Conclusions}

Recent researchers have not borne out these fears as far as effects on cognitive functions, although concerns persist about whether fostering aggression or addictive play. The concern is that if we have begun to figure out how a video game or digital game improves cognition in players or naive people by bettering attention, and how are reaction times on "making a decision" and memory without using the conventional or violent video games [46].

Cognitive dysfunction is a frequent adverse event in the postoperative period, especially in elderly patients. The tests commonly utilized for the detection of postoperative cognitive dysfunction (POCD) are time-consuming. What limits 
their routine use? Consequently, there is a limitation to adopt measures to increase preoperative cognitive reserve and rehabilitation of POCD. That situation is an incentive to search for alternative diagnosis methods to overcome that limitation. Digital games have the potential neuromodulator effect and have used as an alternative to the psychotherapeutic treatment and rehabilitation of cognitive skills [39] [47]. However, the experience with these games to assess the integrity of perioperative neuropsychological functions is still scarce. It hypothesized that a digital game could replace the common neuropsychological tests for detecting POCD.

So, we started to design the nonviolent game geared toward people with brain injuries or cognitive deficits as a POCD. Considering this capable of digital games offer, we create the MentalPlus ${ }^{\circledast}$ digital game. This tool is very useful to multitask required, improve the executive attention and memory functions. MentalPlus ${ }^{\circledast}$ was created first to evaluate this cognitive functions in POCD but due to its high usefulness for rehabilitation, created twelve themes similar with the first to propose the proper rehabilitation way. MentalPlus ${ }^{\varpi}$ digital game is set up with the aim of being a tool for the cognitive evaluation in a fun way. It based upon rules, tasks, planning and the search for strategies for making a decision. It evaluates the cognitive performance through memory, attention and executive functions.

Regarding the brain response associated with the MentalPlus ${ }^{\circledast}$ as a training game, it suggested that there would be the modulation of the connectivity by the performance of anterior cingulate and medial frontal gyrus during the executive function task. There will also be the greater connectivity modulated by the fulfillment of the prefrontal cortex and hippocampus for long-term memories. Connectivity is accentuated by the performance of the temporal lobe and frontal cortex for the semantic memories (long-term stored events) and connectivity cerebellum of the base and ganglia to the motor cortex procedural memory and the modulated connectivity of the prefrontal cortex to the attention functions. The MentalPlus ${ }^{\circledast}$ has been a focus for researchers that want to develop a tool for the brain rehabilitation. It is one-way for reorganization and neuroplasticity brain and is registered on ClinicalTrials.gov Identifier: NCT02551952.

So, games stimulate the cognitive function and enhance skills such as creativity, strategies search, decision-making, and visual perception. They can be used as tools for encouraging and improving expertise and abilities of neuropsychological functions, and they induce changes in structure and function of brain architecture.

Researchers at the Max Planck Institute conducted the research on the effect of video games on the human brain and realized that it had been no change in the brains of some participating volunteers through the MRI technique [48]. Otherwise, the study revealed a volumetric increase in brain areas in a group of players. The increase in gray matter is noted in particular areas of the right hippocampal formation, the right dorsolateral prefrontal cortex, and the bilateral cerebellum. These brain areas directly linked to neuropsychological functions 
responsible for planning strategies to solve problems, body coordination command, visuospatial and memory formation.

Concluding, there are several studies and research centers properly analyzing video games for the stimulation of cognitive functions. Virtual games are a breakthrough technology and a challenge for medicine. Thus, digital games might bring many benefits, but it is necessary to evaluate the purpose for what it is indicated.

\section{References}

[1] Julvez, J., Paus, T., Bellinger, D., Eskenazi, B., Tiemeier, H., Pearce, N., et al. (2016) Environment and Brain Development: Challenges in the Global Context. Neuroepidemiology, 46, 79-82. https://doi.org/10.1159/000442256

[2] Willey, J.Z. and Mayer, S.A. (2011) Brain Injury Clinical Trials: New Agents or New Statistics? Critical Care, 15, 188. https://doi.org/10.1186/cc10350

[3] Woolpert, D. and Reilly, J.S. (2016) Investigating the Extent of Neuroplasticity: Writing in Children with Perinatal Stroke. Neuropsychologia, 89, 105-118.

[4] Cioni, G., D’Acunto, G. and Guzzetta, A. (2011) Perinatal Brain Damage in Children: Neuroplasticity, Early Intervention, and Molecular Mechanisms of Recovery. Progress in Brain Research, 189, 139-154.

[5] Thayer, R.E. and Feldstein Ewing, S.W. (2016) Adolescent Psychotherapy for Addiction Medicine: From Brain Development to Neurocognitive Treatment Mechanisms. Progress in Brain Research, 224, 305-322.

[6] Borroto-Escuela, D.O., Wydra, K., Pintsuk, J., Narvaez, M., Corrales, F., Zaniewska, M., et al. (2016) Understanding the Functional Plasticity in Neural Networks of the Basal Ganglia in Cocaine Use Disorder: A Role for Allosteric Receptor-Receptor Interactions in A2A-D2 Heteroreceptor Complexes. Neural Plasticity, 2016, Article ID: 4827268. https://doi.org/10.1155/2016/4827268

[7] Bertrand, P.P., Polglaze, K.E., Chen, H., Sandow, S.L., Walduck, A., Jenkins, T.A., et al. (2016) Excitability and Synaptic Transmission in the Enteric Nervous System: Does Diet Play a Role? In: Brierley, S. and Costa, M., Eds., The Enteric Nervous System, Advances in Experimental Medicine and Biology, Vol. 891, Springer International Publishing, Switzerland, 201-211. https://doi.org/10.1007/978-3-319-27592-5_19

[8] Snyder, S.H. (2017) A Life of Neurotransmitters. Annual Review of Pharmacology and Toxicology, 57, 1-11.

https://doi.org/10.1146/annurev-pharmtox-010716-104511

[9] Ukken, F.P., Bruckner, J.J., Weir, K.L., Hope, S.J., Sison, S.L., Birschbach, R.M., et al. (2016) BAR-SH3 Sorting Nexins Are Conserved Interacting Proteins of Nervous Wreck That Organize Synapses and Promote Neurotransmission. Journal of Cell Science, 129, 166-177.

[10] Reid, L.B., Rose, S.E. and Boyd, R.N. (2015) Rehabilitation and Neuroplasticity in Children with Unilateral Cerebral Palsy. Nature Reviews Neurology, 11, 390-400. https://doi.org/10.1038/nrneurol.2015.97

[11] Takeuchi, N., Izumi, S.I., Ota, J. and Ueda, J. (2016) Neural Plasticity on Body Representations: Advancing Translational Rehabilitation. Neural Plasticity, 2016, Article ID: 9737569.

[12] Degeilh, F., Eustache, F. and Guillery-Girard, B. (2015) Le developpement cognitif et cerebral de la memoire: De l'enfance a l'age adulte [Cognitive and Brain Develop- 
ment of Memory from Infancy to Early Adulthood]. Biologie Aujourd hui, 209, 249-260.

[13] Cocks, G., Carta, M.G., Arias-Carrion, O. and Nardi, A.E. (2016) Neural Plasticity and Neurogenesis in Mental Disorders. Neural Plasticity, 2016, Article ID: 3738015. https://doi.org/10.1155/2016/3738015

[14] Wenger, Y., Buzgariu, W. and Galliot, B. (2016) Loss of Neurogenesis in Hydra Leads to Compensatory Regulation of Neurogenic And Neurotransmission Genes in Epithelial Cells. Philosophical transactions of the Royal Society of London. Series B, 371, Article ID: 20150040. https://doi.org/10.1098/rstb.2015.0040

[15] Bhangra, K.S., Busuttil, F., Phillips, J.B. and Rahim, A.A. (2016) Using Stem Cells to Grow Artificial Tissue for Peripheral Nerve Repair. Stem Cells International, 2016, Article ID: 7502178. https://doi.org/10.1155/2016/7502178

[16] Niibori, Y., Yu, T.S., Epp, J.R., Akers, K.G., Josselyn, S.A. and Frankland, P.W. (2012) Suppression of Adult Neurogenesis Impairs Population Coding of Similar Contexts in Hippocampal CA3 Region. Nature Communications, 3, Article No. 1253. https://doi.org/10.1038/ncomms2261

[17] Yi, C.A., Lee, K.S., Lee, H.Y., Kim, S., Kwon, O.J., Kim, H., et al. (2013) Coregistered Whole Body Magnetic Resonance Imaging-Positron Emission Tomography (MRIPET) versus PET-Computed Tomography plus Brain MRI in Staging Resectable Lung Cancer: Comparisons of Clinical Effectiveness in a Randomized Trial. Cancer, 119, 1784-1791. https://doi.org/10.1002/cncr.28000

[18] Bajrami, A., Azman, F., Yayla, V., Cagirici, S., Keskinkilic, C. and Sozer, N. (2016) MRI Findings and Cognitive Functions in a Small Cohort of Myotonic Dystrophy Type 1: Retrospective Analyses. The Neuroradiology Journal, 30, 23-27. https://doi.org/10.1177/1971400916678223

[19] Barman, A., Chatterjee, A. and Bhide, R. (2016) Cognitive Impairment and Rehabilitation Strategies after Traumatic Brain Injury. Indian Journal of Psychological Medicine, 38, 172-181. https://doi.org/10.4103/0253-7176.183086

[20] Whyte, J. (2002) Traumatic Brain Injury Rehabilitation: Are There Alternatives to Randomized Clinical Trials? Archives of Physical Medicine and Rehabilitation, 83, 1320-1322. https://doi.org/10.1053/apmr.2002.34807

[21] das Nair, R., Cogger, H., Worthington, E. and Lincoln, N.B. (2016) Cognitive Rehabilitation for Memory Deficits after Stroke. The Cochrane Database of Systematic Reviews, 9, CD002293.

[22] Balaz, M., Bockova, M., Rektorova, I. and Rektor, I. (2011) Involvement of the Subthalamic Nucleus in Cognitive Functions-A Concept. Journal of the Neurological Sciences, 310, 96-99. https://doi.org/10.1016/j.jns.2011.07.016

[23] Friedman, N.P. and Miyake, A. (2017) Unity and Diversity of Executive Functions: Individual Differences as a Window on Cognitive Structure. Cortex, 86, 186-204.

[24] Baddeley, A. (2010) Working Memory. Current Biology, 20, R136-R140. https://doi.org/10.1016/j.cub.2009.12.014

[25] Baddeley, A.D. and Patterson, K. (1971) The Relation between Long-Term and Short-Term Memory. British Medical Bulletin, 27, 237-242. https://doi.org/10.1093/oxfordjournals.bmb.a070860

[26] Davidson, C.A., Johannesen, J.K. and Fiszdon, J.M. (2016) Role of Learning Potential in Cognitive Remediation: Construct and Predictive Validity. Schizophrenia Research, 171, 117-124. https://doi.org/10.1016/j.schres.2016.01.044

[27] Khazaee, A., Ebrahimzadeh, A. and Babajani-Feremi, A. (2016) Application of Advanced Machine Learning Methods on Resting-State fMRI Network for Identifica- 
tion of Mild Cognitive Impairment and Alzheimer's Disease. Brain Imaging and Behavior, 10, 799-817. https://doi.org/10.1007/s11682-015-9448-7

[28] Loubinoux, I., Carel, C., Pariente, J., Dechaumont, S., Albucher, J.F., Marque, P., et al. (2003) Correlation between Cerebral Reorganization and Motor Recovery after Subcortical Infarcts. NeuroImage, 20, 2166-2180.

[29] Collignon, O., Lassonde, M., Lepore, F., Bastien, D. and Veraart, C. (2007) Functional Cerebral Reorganization for Auditory Spatial Processing and Auditory Substitution of Vision in Early Blind Subjects. Cerebral Cortex, 17, 457-465.

https://doi.org/10.1093/cercor/bhj162

[30] Heller, S.L., Heier, L.A., Watts, R., Schwartz, T.H., Zelenko, N., Doyle, W., et al. (2005) Evidence of Cerebral Reorganization Following Perinatal Stroke Demonstrated with fMRI and DTI Tractography. Clinical Imaging, 29, 283-287. https://doi.org/10.1016/j.clinimag.2004.09.003

[31] Valentin, L.S., Pereira, V.F., Pietrobon, R.S., Schmidt, A.P., Oses, J.P., Portela, L.V., et al. (2016) Effects of Single Low Dose of Dexamethasone before Noncardiac and Nonneurologic Surgery and General Anesthesia on Postoperative Cognitive Dysfunction-A Phase III Double Blind, Randomized Clinical Trial. PLoS ONE, 11, e0152308. https://doi.org/10.1371/journal.pone.0152308

[32] Wolchik, S.A., Tein, J.Y., Sandler, I.N. and Kim, H.J. (2016) Developmental Cascade Models of a Parenting-Focused Program for Divorced Families on Mental Health Problems and Substance Use in Emerging Adulthood. Development and Psychopathology, 28, 869-888. https://doi.org/10.1017/S0954579416000365

[33] Stjernsward, S. and Hansson, L. (2017) User Value and Usability of a Web-Based Mindfulness Intervention for Families Living with Mental Health Problems. Health \& Social Care in the Community, 25, 700-709. https://doi.org/10.1111/hsc. 12360

[34] Thibaut, A., Russo, C., Morales-Quezada, L., Hurtado-Puerto, A., Deitos, A., Freedman, S., et al. (2016) Neural Signature of tDCS, tPCS and Their Combination: Comparing the Effects on Neural Plasticity. Neuroscience Letters, 637, 207-214.

[35] Makransky, G., Thisgaard, M.W. and Gadegaard, H. (2016) Virtual Simulations as Preparation for Lab Exercises: Assessing Learning of Key Laboratory Skills in Microbiology and Improvement of Essential Non-Cognitive Skills. PLoS ONE, 11, e0155895. https://doi.org/10.1371/journal.pone.0155895

[36] Mathias, B., Tillmann, B. and Palmer, C. (2016) Sensory, Cognitive, and Sensorimotor Learning Effects in Recognition Memory for Music. Journal of Cognitive Neuroscience, 28, 1111-1126. https://doi.org/10.1162/jocn_a_00958

[37] Shaw, D.R. (2016) A Systematic Review of Pediatric Cognitive Rehabilitation in the Elementary and Middle School Systems. NeuroRehabilitation, 39, 119-123. https://doi.org/10.3233/NRE-161343

[38] Newcombe, F., Brooks, N. and Baddeley, A. (1980) Rehabilitation after Brain Damage: An Overview. International Rehabilitation Medicine, 2, 133-137. https://doi.org/10.3109/09638288009163973

[39] Ballesteros, S., Mayas, J., Prieto, A., Toril, P., Pita, C., Laura Pde, L., et al. (2015) A Randomized Controlled Trial of Brain Training with Non-Action Video Games in Older Adults: Results of the 3-Month Follow-Up. Frontiers in Aging Neuroscience, 7, 45. https://doi.org/10.3389/fnagi.2015.00045

[40] Dedoncker, J., Brunoni, A.R., Baeken, C. and Vanderhasselt, M.A. (2016) The Effect of the Interval-between-Sessions on Prefrontal Transcranial Direct Current Stimulation (tDCS) on Cognitive Outcomes: A Systematic Review and Meta-Analysis. Journal of Neural Transmission (Vienna), 123, 1159-1172.

https://doi.org/10.1007/s00702-016-1558-x 
[41] Graham, A.R. and Benninger, W.B. (2016) Parental Perceptions of the Efficacy of Cogmed Working Memory Training. Applied Neuropsychology: Child, 5, 173-179. https://doi.org/10.1080/21622965.2016.1167505

[42] Monnier, D. (2013) Les jeux video contre le declin cognitif [Using Video Games to Prevent Cognitive Decline]. Soins Gérontologie, No. 102, 8.

[43] Unsworth, N., Redick, T.S., McMillan, B.D., Hambrick, D.Z., Kane, M.J. and Engle, R.W. (2015) Is Playing Video Games Related to Cognitive Abilities? Psychological Science, 26, 759-774. https://doi.org/10.1177/0956797615570367

[44] Mishra, J., Anguera, J.A. and Gazzaley, A. (2016) Video Games for Neuro-Cognitive Optimization. Neuron, 90, 214-218. https://doi.org/10.1016/j.neuron.2016.04.010

[45] Shams, T.A., Foussias, G., Zawadzki, J.A., Marshe, V.S., Siddiqui, I., Muller, D.J., et al. (2015) The Effects of Video Games on Cognition and Brain Structure: Potential Implications for Neuropsychiatric Disorders. Current Psychiatry Reports, 17, 71. https://doi.org/10.1007/s11920-015-0609-6

[46] Mathiak, K. and Weber, R. (2006) Toward Brain Correlates of Natural Behavior: fMRI during Violent Video Games. Human Brain Mapping, 27, 948-956. https://doi.org/10.1002/hbm.20234

[47] Ballesteros, S., Prieto, A., Mayas, J., Toril, P., Pita, C., Ponce de Leon, L., et al. (2014) Brain Training with Non-Action Video Games Enhances Aspects of Cognition in Older Adults: A Randomized Controlled Trial. Frontiers in Aging Neuroscience, 6, 277. https://doi.org/10.3389/fnagi.2014.00277

[48] Kuhn, S., Gleich, T., Lorenz, R.C., Lindenberger, U. and Gallinat, J. (2014) Playing Super Mario Induces Structural Brain Plasticity: Gray Matter Changes Resulting from Training with a Commercial Video Game. Molecular Psychiatry, 19, 265-271. https://doi.org/10.1038/mp.2013.120

\section{Abbreviations and Acronyms}

postoperative cognitive dysfunction (POCD); Transcranial direct-current stimulation (tDCS); Transcranial Magnetic Stimulation (TMS).

\section{Submit or recommend next manuscript to SCIRP and we will provide best service for you:}

Accepting pre-submission inquiries through Email, Facebook, LinkedIn, Twitter, etc. A wide selection of journals (inclusive of 9 subjects, more than 200 journals)

Providing 24-hour high-quality service

User-friendly online submission system

Fair and swift peer-review system

Efficient typesetting and proofreading procedure

Display of the result of downloads and visits, as well as the number of cited articles

Maximum dissemination of your research work

Submit your manuscript at: http://papersubmission.scirp.org/

Or contact ojmp@scirp.org 